\title{
Sensenbrenner Syndrome Presenting with Severe Anorexia, Failure to Thrive, Chronic Kidney Disease and Angel-Shaped Middle Phalanges in Two Siblings
}

\author{
Miroslava Brndiarova ${ }^{a}$ Martin Mraz $^{b}$ Zuzana Kolkova ${ }^{c}$ Frantisek Cisarik $^{d}$ \\ Peter Banovcin ${ }^{\mathrm{a}}$

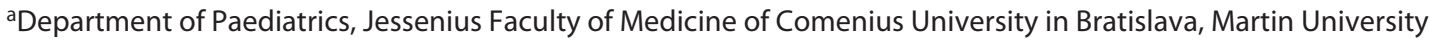 \\ Hospital, Martin, Slovakia; 'Department of Paediatric and Adolescent Medicine, Children`s University Hospital, \\ Kosice, Slovakia; 'Biomedical Center, Jessenius Faculty of Medicine of Comenius University in Bratislava, Bratislava, \\ Slovakia; ${ }^{\mathrm{d}}$ eppartment of Genetics, University Hospital in Zilina, Zilina, Slovakia
}

\section{Established Facts}

- Sensenbrenner syndrome is a very rare autosomal recessive disorder. Significant renal impairment due to progressive tubulointerstitial nephritis (nephronopthisis) may be present at a very early age.

- Angel-shaped phalangoepiphyseal dysplasia has been typically described in patients with variants in the growth differentiation factor 5 (GDF5) gene rather than WDR35 gene.

\section{Novel Insights}

- This is the first report of Sensenbrenner syndrome (WDR35 variant) presenting with severe anorexia and failure to thrive.

- Angel-shaped middle phalanges have not been described in patients with Sensenbrenner syndrome and may represent an overlapping phenotypic manifestation of ciliopathy.

\section{Keywords}

Sensenbrenner syndrome - Anorexia - Failure to thrive . Chronic kidney disease . Angel-shaped middle phalanges

\section{Abstract \\ Sensenbrenner syndrome is a very rare autosomal recessive disorder caused by variants in genes involved in the func- tional development of primary cilia. Typical clinical manifes-}

tations include craniofacial and skeletal abnormalities, hence the alternative name cranioectodermal dysplasia. Chronic kidney disease due to progressive tubulointerstitial nephritis (nephronophthisis) has been described in these patients. The authors present 2 siblings with severe anorexia, failure to thrive, chronic kidney disease, and angel-shaped middle phalanges. Two previously described variants $p$. (Leu641*) and p.(Asp841Val) were identified in the WDR35 gene which is most commonly affected in this condition. karger@karger.com

(C) 2021 S. Karger AG, Basel

www.karger.com/msy

Karger ${ }^{\prime}=$
Correspondence to:

Miroslava Brndiarova, mirkabdc@gmail.com

Martin Mraz, martin.mraz@dfnkosice.sk 
Analysis of all coding exons of the GDF5 gene was normal. This is the first report of Sensenbrenner syndrome presenting with severe anorexia and failure to thrive at early age. Angel-shaped middle phalanges in the absence of the GDF5 variant may represent an overlapping phenotypic manifestation of ciliopathy.

(c) 2021 S. Karger AG, Basel

\section{Introduction}

Sensenbrenner syndrome is a very rare autosomal recessive ciliopathy. More than 60 patients have been described in the literature [Sensenbrenner et al., 1975]. Variants in 6 genes including IFT122, IFT43, IFT140, IFT52, WDR19, and WDR35 have been identified in patients with Sensenbrenner syndrome so far [Gilissen et al., 2010; Walczak-Sztulpa et al., 2010, 2020]. Mutations in WDR35 and IFT122 are the most common cause of cranioectodermal dysplasia (CED). All of these genes encode proteins that are important in intraflagellar transport [Ruiz-Perez et al., 2007; Walczak-Sztulpa et al., 2020].

Typical clinical manifestations of Sensenbrenner syndrome include dolichocephaly, narrow thorax, rhizomelic micromelia, facial dysmorphia (epicanthic folds, hypotelorism), brachydactyly, syndactyly, abnormal fingernails and toenails as well as dental anomalies [Sensenbrenner et al., 1975]. Chronic kidney disease with progressive tubulointerstitial nephritis (nephronopthisis) may be present at a very early age [Obikane et al., 2006]. Other rare manifestations include hepatic cysts with fibrosis [Zaffanello et al., 2006], recurrent lung infections and respiratory failure [Tamai et al., 2002], heart defects, and ocular anomalies (retinitis pigmentosa) [Eke et al., 1996; Costet et al., 2000]. Most affected children have normal neurological development, though cases with intellectual disability have been described in the literature [Fehrenbach et al., 2014; Li et al., 2015]. Prognosis of CED mainly depends on renal and liver insufficiency [Tamai et al., 2002; Obikane et al., 2006].

Angel-shaped phalangoepiphyseal dysplasia (ASPED) is a rare autosomal dominant form of acromelic dysplasia, characterized by a metacarpophalangeal pattern profile mainly affecting the first metacarpals and middle phalanges of second, third, and fifth digits which all appear short; epiphyseal changes in the hips; abnormal dentition, and delayed bone growth [Giedion et al., 1993]. The diagnosis of ASPED is confirmed by the presence of typical features on skeletal X-ray [Holder-Espinasse et al., 2004].
It is caused by defects in the growth differentiation factor 5 gene (GDF5) critical for bone growth and cartilage and joint morphogenesis. Angel-shaped middle phalanges have not been described in patients with Sensenbrenner syndrome.

\section{Clinical Report}

\section{Patient 1}

The male patient was born after a second uneventful pregnancy to consanguineous parents (they are third cousins) at 38 weeks with a birth weight of $4,130 \mathrm{~g}$ (50th centile), length $51 \mathrm{~cm}$ (97th centile), and a head circumference of $37 \mathrm{~cm}$ (97th centile). Postnatal adaptation was normal. Typical skeletal abnormalities of CED including osteochondrodysplasia, dolichocephaly, prominent forehead, low-set ears, short neck, narrow thorax, brachydactyly, syndactyly of the second and third toes, dysmorphic facial features (epicanthic folds, hypotelorism), and hypospadias were present immediately after birth (Fig. 1 a,b). X-ray showed angel-shaped middle phalanges of the II-V fingers of both hands (Fig. 1e). Postnatal renal ultrasound showed normal-sized kidneys with increased parenchymal echogenicity. The boy developed a transient episode of acute kidney injury with maximum creatinine of 108 $\mu \mathrm{mol} / \mathrm{L}$ (reference range $23-68 \mu \mathrm{mol} / \mathrm{L}$ ) which resolved completely. Within the first years of life, he suffered from severe anorexia, vomiting, and failure to thrive. At the age of 1 year, his weight was $9,340 \mathrm{~g}$ (25th centile) and length $75 \mathrm{~cm}$ (25th centile). Dentition was delayed and his teeth were small. At the age of 4 years, he developed hypertension with maximum systolic blood pressure of $135 \mathrm{mmHg}$. Renal biopsy at the age of 9 years confirmed tubulointerstitial nephritis with a moderate degree of chronic changes in renal parenchyma. At 11 years of age, his weight was $32.5 \mathrm{~kg}$ (10th centile) and length $143.5 \mathrm{~cm}$ (25th centile). He was treated for hypertension and chronic kidney disease (creatinine $210 \mu \mathrm{mol} / \mathrm{L}$; reference range $23-68 \mu \mathrm{mol} / \mathrm{L}$ ). His urine output and dipstick were normal. The follow-up ultrasound showed normal-sized kidneys with increased parenchymal echogenicity. He showed normal neurodevelopment. Recurrent respiratory infections (rhinosinusitis) were observed. Ciliary motility measured using Cilial Analysis software (LabVIEW ${ }^{\mathrm{TM}}$ ) [Hargas et al., 2011] was reduced with a beat frequency of $5.6 \mathrm{~Hz}$ (normal value $7-12 \mathrm{~Hz}$ ).

\section{Patient 2}

Sibling of patient 1 was born after a third uneventful pregnancy at 41 weeks. His birth weight was $4,470 \mathrm{~g}$ (90th centile), length $50 \mathrm{~cm}$ (10th centile), and he had a head circumference of $38.5 \mathrm{~cm}$ (97th centile). Postnatal adaptation was normal. Typical skeletal abnormalities of CED were diagnosed antenatally. Osteochondrodysplasia, dolichocephaly, prominent forehead, low-set ears, short neck, narrow thorax, brachydactyly, syndactyly of the second and third toes, and dysmorphic facial features (epicanthic folds, hypotelorism) were present (Fig. 1c, d). X-ray confirmed angel-shaped middle phalanges of the II-V digits of both hands. Postnatal renal ultrasound showed normal-sized kidneys with increased parenchymal echogenicity. The dominant clinical features within the first months of life were anorexia and vomiting. A nasogastric tube was inserted due to failure to thrive at the age of 2 months. Dentition was delayed and his teeth were small. At the age of 3 years, his 

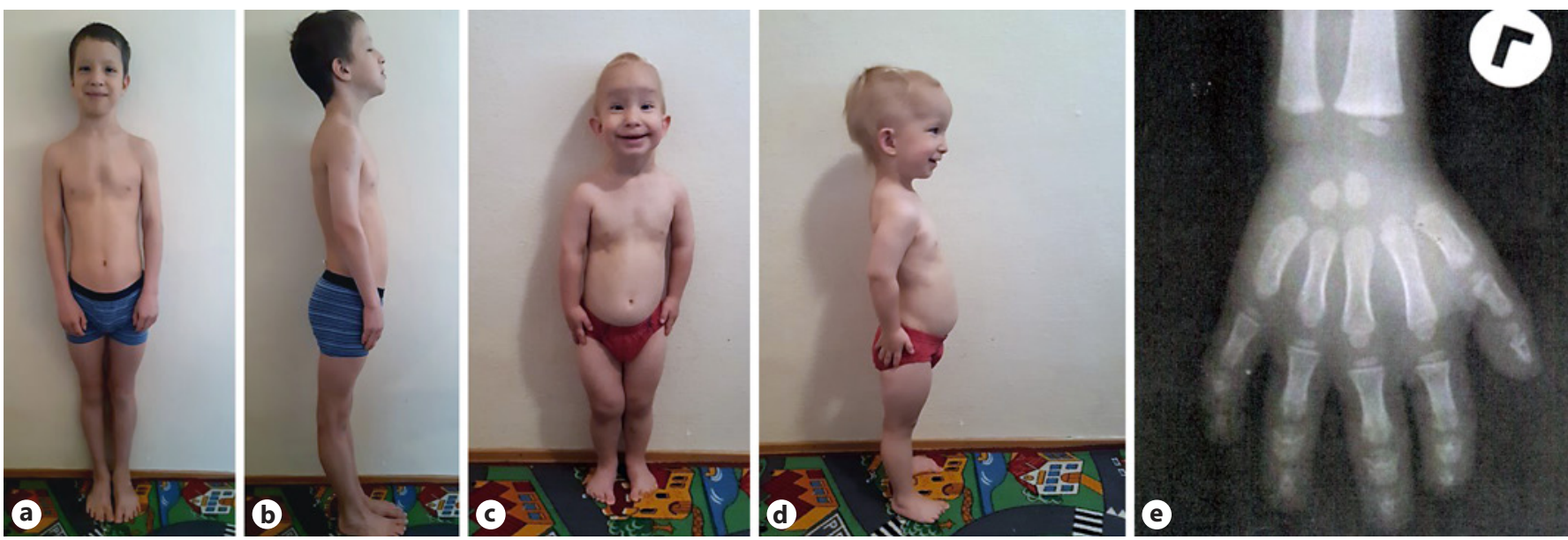

Fig. 1. a, b Dysmorphic features (osteochondrodysplasia, dolichocephaly, prominent forehead, low-set ears, short neck, narrow thorax, brachydactyly, syndactyly of the second and third toes, epicanthic folds, hypotelorism) in patient 1 at the age of 11 years. $\mathbf{c}$, d Patient 2 at the age of 3 years with angel-shaped middle phalanges in digits II-V of both hands. e X-ray of the hand, patient 1.

weight was $12 \mathrm{~kg}$ (<3rd centile) and height $90 \mathrm{~cm}$ (3rd centile). Renal function (creatinine $47 \mu \mathrm{mol} / \mathrm{L}$; reference range 23-68 $\mu \mathrm{mol} / \mathrm{L})$ and blood pressure $(90 / 42 \mathrm{mmHg}$ ) were normal. The follow-up ultrasound showed normal-sized kidneys with increased parenchymal echogenicity. The patient showed normal neurodevelopment. Ciliary motility measured using Cilial Analysis software (LabVIEW ${ }^{\mathrm{TM}}$ ) [Hargas et al., 2011] was normal with a beat frequency of $7.5 \mathrm{~Hz}$ (normal value $7-12 \mathrm{~Hz}$ ).

\section{Genetic Analysis}

Screening of 4 genes (WDR35, IFT122, WDR19, IFT43) was performed in patient 1 using a next-generation sequencing method (NextSeq system; Illumina, San Diego, CA, USA). Entire coding and splice-relevant regions of the genes were analyzed. Two variants in heterozygous state were detected in the WDR35 gene (NM001006657.1). The c.1922T>G (p.Leu641*) variant in exon 18 is listed in the population databases dbSNP (rs199952377) and gno$\mathrm{mAD}(0.020 \%)$, and based on clinical studies listed in the ClinVar (ID: 65,619) database as a pathogenic variant. The c.2522A $>\mathrm{T}$ (p.Asp841 Val) change in exon 22 is not listed in the dbSNP or gnomAD databases. However, based on clinical studies, ClinVar (ID: 65,619), this variant is defined as pathogenic. Examination of the WDR35 gene was performed in patient 2 using a next-generation sequencing method (NextSeq system, Illumina). The presence of both variants was confirmed. Segregation analysis revealed that the p.(Leu641*) variant was paternally inherited, and the p.(Asp841 Val) change was mater- nally inherited. This variant was also identified in 2 healthy siblings (older brother and younger sister).

In both patients, the coding regions of GDF5 were analyzed by Sanger sequencing on ABI3500 Genetic Analyzer (Applied Biosystems, Foster City, CA, USA). All coding exons of the GDF5 gene were analyzed. The primers were designed to encompass, in particular, exons 3 and 4 together with their flanking intron-exon junctions. The sequencing results data were evaluated using Chromas software and compared with the corresponding reference sequence (NC_000020.11). No causal variants were identified.

\section{Discussion}

Herein, we report 2 siblings with Sensenbrenner syndrome with anorexia and failure to thrive throughout infancy. This feature has not been described in the literature before. As the main causes of anorexia have been ruled out (cystic fibrosis, celiac disease), we hypothesize that anorexia could be a manifestation of Sensenbrenner syndrome present at an early age.

Interestingly, both siblings have phenotypic manifestation of Sensenbrenner syndrome and angel-shaped middle phalanges. Sensenbrenner syndrome and ASPED have several features in common. Abnormal dentition and delayed bone growth, acromelic dysplasia, characterized by a metacarpophalangeal pattern profile was not observed in patients with Sensenbrenner syndrome. The di- 


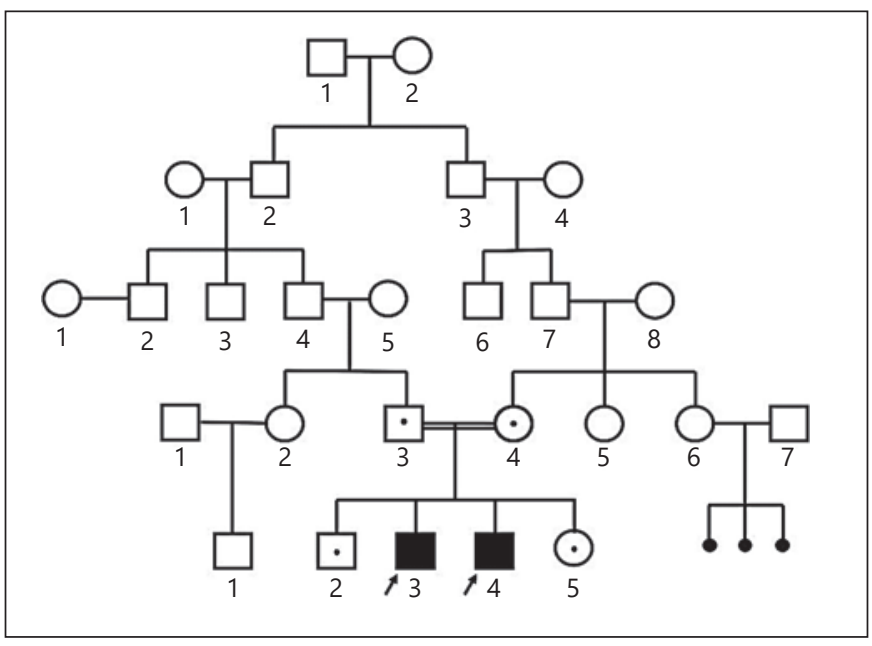

Fig. 2. Pedigree of the family and relationships in individual generations.

agnosis of CED is obvious in the herein reported patients. However, it is sometimes difficult to make a definitive diagnosis because the clinical signs of skeletal ciliopathies overlap [Handa et al., 2020]. In addition, phenotypic features are variable even in patients with the same mutations. In patients described in this clinical report, 2 heterozygous mutations in the WRD35 gene, a nonsense mutation p.(Leu641*) and a missense mutation p. (Asp841Val), were detected. These variants are listed in the ClinVar database. Both variants have previously been described in patients with Sensenbrenner syndrome [Hoffer et al., 2013; Li et al., 2015; Walczak-Sztulpa et al., 2017, 2018, 2020, 2021]. Walczak-Sztulpa et al. [2017] presented intrafamilial variability in siblings with these variants. It contributes to the hypothesis that additional mutations in other genes ("genetic load") can modulate the clinical manifestation and explain inter- and intrafamilial phenotypes. On the other hand, there are also nongenetic factors that may influence expression of relevant genes [Bredrup at al., 2011; Arts and Knoers, 2013]. Observed angel-shaped middle phalanges may represent an overlapping phenotypic manifestation of ciliopathy. We hypothesize it could also be a consequence of mutation in another gene responsible for proper morphogenesis of bones, cartilage, and joints. Whole-exome sequencing could provide an answer to this hypothesis.

Since both patients are compound heterozygotes for the WDR35 mutations, it is obvious that inherited alleles are not identical by descent, although their parents are distant relatives; they are third cousins (Fig. 2). The risk of the offspring of third cousins is comparable to the gen- eral population, as the probability of carrying identical mutations decreases with the decreasing degree of relatedness [Shawky et al., 2013].

According to the literature, many cilia-associated proteins found in primary cilia are also found in motile cilia [Fliegauf et al., 2006; Driscoll et al., 2008]. These are primarily proteins needed for the ciliary base such as the transition zone or basal bodies or proteins important for intraflagellar transport [Kempeneers and Chilvers, 2018]. According to observations by Li et al. [2015], WDR35 deficiency disrupted ciliogenesis in the airway. Ciliogenesis was largely blocked and few cilia formed exhibiting slow dyskinetic ciliary motion. Therefore, we evaluated the ciliary beat frequency. Only patient 1 had a reduced ciliary beat frequency. There may be factors other than WDR35 affecting ciliary function which have not been described to date. It is known that chronic kidney disease is associated with ciliary dysfunction. This is supported by findings from Kucur et al. [2016] that chronic kidney disease may be one of the risk factors for mucociliary clearance dysfunction.

\section{Summary}

Ciliogenesis is rather complex process that can be influenced by several factors, not all of which are known to date. The phenotype of various ciliopathies may overlap. Sensenbrenner syndrome is a rare primary ciliopathy. The clinical picture is easily recognizable in most patients. New phenotypic manifestations described here (anorexia, failure to thrive, angel-shaped middle phalanges) may occur.

\section{Acknowledgments}

We would like to thank Katarina Machalekova, $\mathrm{MD}, \mathrm{PhD}$ at the Institute of Pathology, St. Elisabeth Cancer Institute in Bratislava, Slovakia, for renal biopsy analysis, and Zora Lasabova, Assoc. Prof., RNDr., PhD. at the Department of Molecular Biology and Genomics, Jessenius Faculty of Medicine of Comenius University in Bratislava, Slovakia, for technical support.

\section{Statement of Ethics}

The parents gave their consent to publish this case report. The study protocol was part of a clinical study approved by the Ethics Committee of the Jessenius Faculty of Medicine, Comenius University in Bratislava, Slovakia (study No. EK 1/2020). 


\section{Conflict of Interest Statement}

The authors have no conflicts of interest to declare.

\section{Funding Sources}

There are no sources of funding that need to be reported.

\section{Author Contributions}

Each author participated fully in this case report. All authors concur with this submission and approved the final version of the revised manuscript.

\section{References}

Arts HH, Knoers NV. Current insights into renal ciliopathies: What can genetics teach us?. Pediatr Nephrol. 2013;28(6):863-74.

Bredrup C, Saunier S, Oud MM, Fiskerstrand T, Hoischen A, Brackman D, et al. Ciliopathies with skeletal anomalies and renal insufficiency due to mutations in the IFT-A gene WDR19. Am J Hum Genet. 2011;89(5):63443.

Costet C, Betis F, Berard E, Tsimaratos M, Sigaudy S, Antignac C, et al. Pigmentosum retinis and tubulo-interstitial nephronophthisis in Sensenbrenner syndrome: A case report (in French). J Fr Ophtalmol. 2000;23:158-60.

Driscoll JA, Bhalla S, Liapis H, Ibricevic A, Brody SL. Autosomal dominant polycystic kidney disease is associated with an increased prevalence of radiographic bronchiectasis. Chest. 2008;133(5):1181-8.

Eke T, Woodruff G, Young ID. A new oculorenal syndrome: retinal dystrophy and tubulointerstitial nephropathy in cranioectodermal dysplasia. Br J Ophthalmol. 1996;80(5):490-1.

Fehrenbach H, Decker C, Eisenberger T, Frank V, Hampel T, Walden $\mathrm{U}$, et al. Mutations in WDR19 encoding the intraflagellar transport component IFT144 cause a broad spectrum of ciliopathies. Pediatr Nephrol. 2014;29(8): 1451-6.

Fliegauf M, Horvath J, von Schnakenburg C, Olbrich H, Müller D, Thumfart J, et al. Nephrocystin specifically localizes to the transition zone of renal and respiratory cilia and photoreceptor connecting cilia. J Am Soc Nephrol. 2006;17(9):2424-33.

Giedion A, Prader A, Fliegel C, Krasikov N, Langer L, Poznanski A, et al. Angel-shaped phalango-epiphyseal dysplasia (ASPED): identification of a new genetic bone marker. Am J Med Genet. 1993;47(5):765-71.

Gilissen C, Arts HH, Hoischen A, Spruijt L, Mans $\mathrm{DA}$, Arts $\mathrm{P}$, et al. Exome sequencing identifies WDR35 variants involved in Sensenbrenner syndrome. Am J Hum Genet. 2010;87(3): $418-23$.

Handa A, Voss U, Hammarsjö A, Grigelioniene G, Nishimura G. Skeletal ciliopathies: a pattern recognition approach. Jpn J Radiol. 2020; 38(3):193-206.
Hargas L, Koniar D., Stofan S. Sophisticated biomedical tissue measurement using image analysis and virtual instrumentation. In Folea S,editor. Practical Applications and Solutions using LabVIEW" ${ }^{\text {st }}$ Software. Rijeka: Tech Publisher; 2011. p. 155-180.

Hoffer JL, Fryssira H, Konstantinidou AE, Ropers HH, Tzschach A. Novel WDR35 mutations in patients with cranioectodermal dysplasia (Sensenbrenner syndrome). Clin Genet. 2013;83(1):92-5.

Holder-Espinasse M, Escande F, Mayrargue E, Dieux-Coeslier A, Fron D, Doual-Bisser A, et al. Angel shaped phalangeal dysplasia, hip dysplasia, and positional teeth abnormalities are part of the brachydactyly $\mathrm{C}$ spectrum associated with CDMP-1 mutations. J Med Genet. 2004;41(6):e78-4.

Kempeneers C, Chilvers MA. To beat, or not to beat, that is question! The spectrum of ciliopathies. Pediatr Pulmonol. 2018;53(8):1122-9.

Kucur C, Ozbay I, Gulcan E, Kulekci S, Aksoy S, Oghan F. Evaluation of nasal mucociliary activity in patients with chronic renal failure. Eur Arch Otorhinolaryngol. 2016;273(5): 1167-71.

Li Y, Garrod AS, Madan-Khetarpal S, Sreedher G, McGuire M, Yagi H, et al. Respiratory motile cilia dysfunction in a patient with cranioectodermal dysplasia. Am J Med Genet A. 2015; 167A(9):2188-96.

Obikane K, Nakashima T, Watarai Y, Morita K, Cho K, Tonoki H, et al. Renal failure due to tubulointerstitial nephropathy in an infant with cranioectodermal dysplasia. Pediatr Nephrol. 2006;21(4):574-6.

Ruiz-Perez VL, Blair HJ, Rodriguez-Andres ME, Blanco MJ, Wilson A, Liu YN, et al. Evc is a positive mediator of Ihh-regulated bone growth that localises at the base of chondrocyte cilia. Development. 2007;134(16):290312.

Sensenbrenner JA, Dorst JP, Owens RP. New syndrome of skeletal, dental and hair anomalies. Birth Defects Orig Artic Ser. 1975;11(2):3729.
Shawky RM, Elsayed SM, Zaki ME, Nour El-Din SM, Kamal FM. Consanguinity and its relevance to clinical genetics. Egypt J Med Hum Genet. 2013;14(2):157-64.

Tamai S, Tojo M, Kamimaki T, Sato Y, Nishimura G. Intrafamilial phenotypic variations in cranioectodermal dysplasia: propositus with typical manifestations and her brother with perinatal death. Am J Med Genet. 2002; 107(1):78-80.

Walczak-Sztulpa J, Eggenschwiler J, Osborn D, Brown DA, Emma F, Klingenberg C, et al. Cranioectodermal dysplasia, Sensenbrenner syndrome, is a ciliopathy caused by mutations in the IFT122 gene. Am J Hum Genet. 2010; 86(6):949-56.

Walczak-Sztulpa J, Wawrocka A, Sobierajewicz A, Kuszel L, Zawadzki J, Grenda R, et al. Intrafamilial phenotypic variability in a Polish family with Sensenbrenner syndrome and biallelic WDR35 mutations. Am J Med Genet A. 2017;173(5):1364-8.

Walczak-Sztulpa J, Wawrocka A, Swiader-Lesniak A, Socha M, Jamsheer A, Drozdz D, et al. Clinical and molecular genetic characterization of a male patient with Sensenbrenner syndrome (cranioectodermal dysplasia) and biallelic WDR35 mutations. Birth Defects Res. 2018;110(4):376-81.

Walczak-Sztulpa J, Wawrocka A, Leszczynska B, Mikulska B, Arts HH, Bukowska-Olech E, et al. Prenatal genetic diagnosis of cranioectodermal dysplasia in a Polish family with compound heterozygous variants in WDR35. Am J Med Genet A. 2020;182(10):2417-25.

Walczak-Sztulpa J, Wawrocka A, Stańczyk M, Pesz K, Dudarewicz L, Chrul S, et al. Interfamilial clinical variability in four Polish families with cranioectodermal dysplasia and identical compound heterozygous variants in WDR35. Am J Med Genet A. 2021;185(4): 1195-1203.

Zaffanello M, Diomedi-Camassei F, Melzi ML Torre G, Callea F, Emma F. Sensenbrenner syndrome: A new member of the hepatorenal fibrocystic family. Am J Med Genet A. 2006; 140(21):2336-40 